study was that their susceptibility to all antibiotics (with the important exception of tetracyclines) has remained constant.

There are 12 cephalosporins (including cefoxitin, strictly a cephamycin), of which only five are yet on the British market; among these, much the most active were cephaloridine and cephapirin. Only seven tetracyclines were tested, omitting rolitetracycline (German) and lymecycline and clomocycline (both Italian). It is interesting that chlortetracycline, the original Aureomycin of 1948 and ancestor of the others, had the highest activity of all against the species. The aminoglycosides, of which 11 were tested (not including framycetin or paromomycin), are of less interest because they have little place in treating streptococcal infections except in combination with penicillin for endocarditis due to Streptococcus faecalis. For what it may be worth, far the most active in these tests were gentamicin $C_{1}$, betamicin, sisomicin, verdamicin, and butirosin. Other antibiotics tested (again of little practical interest for this purpose) were polymyxins and spectinomycin. Lincomycin and clindamycin were grouped with six other experimental derivatives, some of which were rather more active. Individual antibiotics of importance also tested were bacitracin; chloramphenicol (but not its derivative thiamphenicol, in use in parts of Western Europe); erythromycin (but not other macrolides such as oleandomycin and spiramycin); rifampicin; and vancomycin. Tests were also done with co-trimoxazole and its two constituents, showing a high degree of synergy between them. In a subsequent paper by the same authors ${ }^{2}$ almost exactly the same 65 agents were used in tests of staphylococci, with very different results, since these organisms are adept at developing resistance.

How is the average prescriber to find his way through this maze? He receives plenty of interested advice through the post and in the more colourful pages of this and other journals. This may enable him to appreciate the merits of an individual new product but not necessarily to assess it rightly in comparison with more familiar remedies. There is sound sense in the advice that the practitioner should confine himself to a few antibacterial drugs and learn well how to use them. Some of the newer ones have general advantages, but others are clearly preferable only for certain non-specific infections, often not common and identifiable only by the laboratory.

${ }^{1}$ Finland, M, et al, Antimicrobial Agents and Chemotherapy, 1976, 9, 11. 2 Sabath, L D, et al, Antimicrobial Agents and Chemotherapy, 1976, 9, 962.

\section{What does the community care about?}

With "participation" the password to respectability in political and intellectual circles in the late 1960s it was inevitable that the reorganised NHS should take account of the trend. Richard Crossman promised that the consumer's voice would be represented, and in consequence the community health councils were grafted on to the multi-tier structure late in its embryogenesis, in an attempt to compensate for the lack of democratic election to the health authorities. In so doing, say Rudolf Klein and Janet Lewis, ${ }^{1}$ the planners added a gothic folly to the palladian mansion-but in such a way as not to destroy the symmetry (as much intellectual as architectural) of the main building.

Klein and Lewis's survey of the councils' early performance can only suggest the ways in which they will develop-CHCs have been working for no more than two years. Naturally enough the hundreds of councils have interpreted their functions and responsibilities in different ways, but already there are pointers to the future.

Who are the members of the CHCs? Half come from local authorities; one-third from voluntary organisations with concerns such as child health, mental illness, and the elderly; and the rest are chosen by regional health authorities. Perhaps we should not be surprised that they are predominantly middle class, middle-aged men-teachers, managers, school governors, and magistrates. Those with political ties are mostly members of the Labour Party. Relatively few are retired, but even so $10 \%$ of members do more than eight hours unpaid work a week. These are the activists in the local community, used to the ways of committees, with contacts in journalism and politics that they know how to exploit.

Again, then, no one should be surprised that many CHCs seem to have behaved as diplomats rather than as aggressive anti-NHS complaints services. That is not to say that councils did not follow up specific complaints by patients-and sometimes by doctors and other NHS staff who felt threatened by health authority plans or victimised by neglect. But Klein and Lewis's survey found that few CHC members were passionately concerned about appointment systems or waiting lists: their energy went into debating with their health authorities the best use of resources-should this or that hospital be closed, should there be a pharmacy in the new health centre, should money be spent on a car park or on kitchens?

Only rarely, moreover, did a CHC set out actually to sample public opinion: most often council members acted as representatives, believing (no doubt sincerely) that their views were those of the community-or at least those that they thought the community ought to hold. Despite their built-in connection with groups such as the mentally handicapped, there is some evidence that CHCs mirror the concerns and prejudices of the middle-aged, middle class professionals from whom they are drawn. Acute illness is their top priority, and Klein and Lewis ${ }^{1}$ warn that, while in theory CHCs may agree with DHSS priorities, in practice they may resist attempts to divert resources away from the acute sector.

Here, perhaps, lies the danger inherent in any real "democratisation" of the NHS. Already some CHC members seem resentful of their lack of effective power and influence; some are pressing for an effective regional and national organisation for $\mathrm{CHCs}^{2}$ (though there is substantial opposition, too). If CHCs do acquire a stronger voice, they may lead the NHS into the trap it has avoided for the last 30 years-the danger of domination by local authority interests. Who is to make the unpopular decisions in the areas and districts if the CHCs can oppose them effectively?

These are still early days, and most councils are still feeling their way in tasks such as monitoring the quality of care, spotlighting deficiencies, and exposing wasteful practices. Their interest in planning and priorities is both natural and reasonable; but a delicate balance has to be drawn between giving the consumer a voice and letting him shout so loudly that no one else can be heard. Perhaps, too, doctors and their professional organisations should try to establish closer contacts with CHCs. Very often their interests and objectives are the same and collaboration may increase the chances of success in pursuing those aims.

${ }^{1}$ Klein, R, and Lewis, J, The Politics of Consumer Representation. London, Centre for Studies in Social Policy, 1976.

${ }^{2}$ Hallas, J, CHCs in Action. London, Nuffield Provincial Hospitals Trust, 1976. 